Check for updates

Cite this: Mater. Chem. Front., 2019, 3, 2032

Received 10th April 2019,

Accepted 4th June 2019

DOI: 10.1039/c9qm00223e

rsc.li/frontiers-materials

\section{T-phase $\mathrm{MoS}_{2}$ quantum dots as a superior co-catalyst to Pt decorated on carbon nitride nanorods for photocatalytic hydrogen evolution from water $\dagger$}

\author{
Zhangqian Liang, Yichen Guo, Yanjun Xue, Hongzhi Cui (D) * and Jian Tian (D) *
}

\section{Introduction}

Due to the emerging energy crisis and global environmental awareness, ${ }^{1-3}$ the conversion of solar energy into perfect hydrogen $\left(\mathrm{H}_{2}\right)$ energy via photocatalytic water splitting using semiconductors as catalysts has attracted significant attention. ${ }^{4-7}$ Hydrogen is considered as an ideal, clean and sustainable candidate to replace exhaustible fossil fuels. ${ }^{8-11}$ Until now, a rich variety of semiconductor materials have been explored as photocatalysts for hydrogen production. ${ }^{12-15}$ As a promising semiconductor photocatalyst, $\mathrm{C}_{3} \mathrm{~N}_{4}$ nanorods (NRs) exhibit a suitable band gap (about $1.38 \mathrm{eV}$ ), broader visible-light absorption range than g- $\mathrm{C}_{3} \mathrm{~N}_{4}$ nanosheets (about $2.47 \mathrm{eV}$ ) and a negative conduction band edge potential (below the reduction potential of $\mathrm{H}_{2} \mathrm{O} / \mathrm{H}_{2}$ ) for splitting water. ${ }^{16,17}$ However, bare $\mathrm{C}_{3} \mathrm{~N}_{4}$ NRs show extremely low activity for the photocatalytic $\mathrm{H}_{2}$ evolution reaction due to the rapid recombination of photogenerated electrons and holes and lack of active sites for photocatalysis. ${ }^{18}$ Integration of co-catalysts, such as noble metals $\mathrm{Au}$ and $\mathrm{Pt}$, into $\mathrm{C}_{3} \mathrm{~N}_{4}$ NRs has proven to be an effective way for suppressing electron-hole

School of Materials Science and Engineering, Shandong University of Science and Technology, Qingdao, 266590, China.E-mail: cuihongzhi1965@163.com, jiantian@sdust.edu.cn

$\dagger$ Electronic supplementary information (ESI) available. See DOI: 10.1039/c9qm00223e recombination and accelerating photocatalytic $\mathrm{H}_{2}$ evolution. ${ }^{19}$ However, the scale-up application of the commonly used noble metal co-catalysts is still largely restricted due to their low abundance and high cost. ${ }^{19,20}$ Therefore, there is in an urgent need to seek noble-metal free alternative co-catalysts compounded with $\mathrm{C}_{3} \mathrm{~N}_{4}$ NRs for synthesizing $\mathrm{C}_{3} \mathrm{~N}_{4}$ NR-based heterostructures with significantly enhanced photocatalytic activity.

As a typical layered transition metal sulfide, molybdenum disulfide $\left(\mathrm{MoS}_{2}\right)$, with a sandwich structure of three stacked atomic layers (S-Mo-S), has been considered a promising alternative for noble-metal co-catalysts due to its abundance and low cost. $^{21-24} \mathrm{MoS}_{2}$ has been designed with various nanostructures, such as nanoparticles, ${ }^{25,26}$ nanowires,${ }^{27,28}$ nanoflowers, ${ }^{29,30}$ nanosheets, ${ }^{31,32}$ and quantum dots (QDs). ${ }^{33,34}$ Interestingly, $\mathrm{MoS}_{2}$ QDS have attracted more significant attention due to their better solubility in aqueous solvents and more edge atoms compared with other $\mathrm{MoS}_{2}$ nanostructures or bulk-MoS $2 \cdot{ }^{35}$ It is well known that $\mathrm{MoS}_{2}$ usually has two phase structures, including a trigonal phase $\left(1 \mathrm{~T}-\mathrm{MoS}_{2}\right)$ and a hexagonal phase $\left(2 \mathrm{H}-\mathrm{MoS}_{2}\right) \cdot{ }^{36,37}$ Natural $\mathrm{MoS}_{2}$ usually exists in the stable $2 \mathrm{H}$ phase, showing semiconducting properties with a tunable bandgap of $1.3-1.9 \mathrm{eV} .{ }^{21}$ However, the inherent semiconducting character of $2 \mathrm{H}-\mathrm{MoS}_{2}$ with a low density of active sites and poor conductivity restricts its catalytic performance. ${ }^{1}$ As reported previously, ${ }^{38} 1 \mathrm{~T}-\mathrm{MoS}_{2}$ offers dense active sites containing catalytically active edges and basal planes, 
while $2 \mathrm{H}-\mathrm{MoS}_{2}$ only possesses edge sites. Besides, compared to $2 \mathrm{H}-\mathrm{MoS}_{2}$, the metallic $1 \mathrm{~T}-\mathrm{MoS}_{2}$ displays excellent conductivity characteristics at ambient temperature, making it suitable as a co-catalyst to accept the electrons for $\mathrm{H}_{2}$ evolution. ${ }^{39}$

This study aims to prepare highly active $\mathrm{MoS}_{2}$ substituting for noble metal Pt for photocatalytic $\mathrm{H}_{2}$ evolution and clearly certify the electron transfer process between $\mathrm{C}_{3} \mathrm{~N}_{4}$ and $\mathrm{MoS}_{2}$. Herein, we prepare 1T- $\mathrm{MoS}_{2}$ QD decorated $\mathrm{C}_{3} \mathrm{~N}_{4}$ NRs (1T-MoS $@$ $\mathrm{C}_{3} \mathrm{~N}_{4}$ NRs) by a sonication-assisted hydrothermal method. The obtained 1T- $\mathrm{MoS}_{2} @ \mathrm{C}_{3} \mathrm{~N}_{4}$ NR composites exhibit a broad visible and near-infrared (NIR) light absorption range, excellent photocurrent response and charge transfer activity. The 1T-MoS $@ \mathrm{C}_{3} \mathrm{~N}_{4}$ NR composite with optimal 1T- $\mathrm{MoS}_{2}$ QD loading of $5.0 \mathrm{wt} \%$ exhibits a drastically enhanced photocatalytic $\mathrm{H}_{2}$ evolution rate of $565 \mu \mathrm{mol} \mathrm{h} \mathrm{h}^{-1} \mathrm{~g}^{-1}$, which is almost 1.8 times higher than that of Pt@ $\mathrm{C}_{3} \mathrm{~N}_{4}$ NRs (318 $\left.\mu \mathrm{mol} \mathrm{h} \mathrm{h}^{-1} \mathrm{~g}^{-1}\right)$ under simulated solar light irradiation, as well as good stability in photocatalytic cyclic runs. The 1T-MoS 2 QDs apparently show metallic characteristics like Pt, and a series of experimental studies have proven the photogenerated electron transfer process and photocatalytic mechanism.

\section{Experimental section}

\subsection{Synthesis of $\mathrm{C}_{3} \mathrm{~N}_{4}$ nanorods (NRs)}

In a typical procedure (Scheme 1), $2.7675 \mathrm{~g}$ of 1,3,5-trichlorotriazine and $0.9459 \mathrm{~g}$ of melamine powder were dissolved in $60 \mathrm{~mL}$ of acetonitrile. The mixture was stirred for $12 \mathrm{~h}$, and then put into a $100 \mathrm{~mL}$ Teflon-lined stainless steel autoclave, which was sealed and maintained at $180{ }^{\circ} \mathrm{C}$ for $96 \mathrm{~h}$. After heating at a certain temperature, the autoclave was allowed to cool to room temperature naturally. The obtained product was sequentially washed with acetonitrile, distilled water and absolute ethanol several times to remove residual impurities and then the resulting powder was dried at $60{ }^{\circ} \mathrm{C}$ for $12 \mathrm{~h}$ to get the final products.

\subsection{Preparation of $1 \mathrm{~T}-\mathrm{MoS}_{2}$ quantum dots (QDs)}

1T- $\mathrm{MoS}_{2}$ QDs were prepared by a simple hydrothermal method (Scheme 2). Specifically, $0.4 \mathrm{~g}$ of $\mathrm{Na}_{2} \mathrm{MoO}_{4} \cdot 2 \mathrm{H}_{2} \mathrm{O}$ and $0.38 \mathrm{~g}$ of $\mathrm{C}_{14} \mathrm{H}_{14} \mathrm{~S}_{2}$ were dissolved in $30 \mathrm{~mL}$ of deionized water and $30 \mathrm{~mL}$ of ethanol with sonication for $30 \mathrm{~min}$, respectively. Then, $\mathrm{C}_{14} \mathrm{H}_{14} \mathrm{~S}_{2}$ solution was added to the $\mathrm{Na}_{2} \mathrm{MoO}_{4} \cdot 2 \mathrm{H}_{2} \mathrm{O}$ solution. After sonication for $30 \mathrm{~min}$, the mixture was then transferred to a $100 \mathrm{~mL}$ Teflon-lined stainless steel autoclave and heated at $180{ }^{\circ} \mathrm{C}$ for $20 \mathrm{~h}$. After the autoclave was cooled to room temperature naturally, the light yellow supernatant was discarded and then

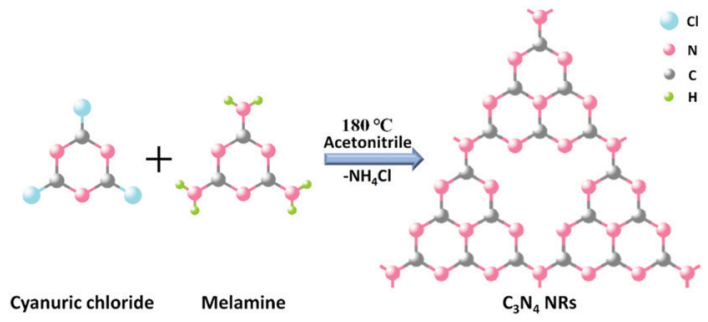

Scheme 1 Schematic illustration of the $\mathrm{C}_{3} \mathrm{~N}_{4}$ NR reaction.

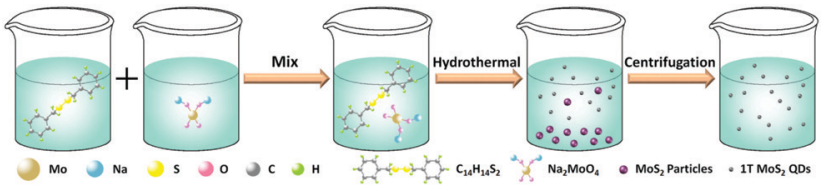

Scheme 2 Schematic illustration of the synthetic route for $1 T-M_{2} S_{2}$ QDs through a hydrothermal technique.

$30 \mathrm{~mL}$ of deionized water was added to disperse the black product. The resulting suspension was then centrifuged for $90 \mathrm{~min}$ at 12000 rpm to separate the supernatant and sediment, and the supernatant was $1 \mathrm{~T}-\mathrm{MoS}_{2}$ QDs. In order to determine the concentration of the $1 \mathrm{~T}-\mathrm{MoS}_{2}$ QD solution, the supernatant was treated by freeze drying to obtain a powder. Therefore, the concentration of the as-prepared 1T-MoS 2 QD solution was determined to be about $0.2 \mathrm{mg} \mathrm{mL}^{-1}$ in terms of the measured weight and the volume of solution before freeze drying.

\subsection{Preparation of $1 \mathrm{~T}-\mathrm{MoS}_{2} @ \mathrm{C}_{3} \mathrm{~N}_{4} \mathrm{NR}$ composites}

$200 \mathrm{mg}$ of $\mathrm{C}_{3} \mathrm{~N}_{4} \mathrm{NRs}$ and $50 \mathrm{~mL}\left(0.2 \mathrm{mg} \mathrm{mL}^{-1}\right)$ of the as-prepared $1 \mathrm{~T}-\mathrm{MoS}_{2}$ QD solution were mixed and then sonicated for over $2 \mathrm{~h}$. Subsequently, the obtained mixture was centrifuged and dried at $60{ }^{\circ} \mathrm{C}$ to gain the target product $\left(1 \mathrm{~T}-\mathrm{MoS}_{2} @ \mathrm{C}_{3} \mathrm{~N}_{4} \mathrm{NRs}\right.$ with $1 \mathrm{~T}-\mathrm{MoS}_{2}$ QD loading of $5.0 \mathrm{wt} \%$ ). Similarly, a series of hybrid catalysts, including 1T-MoS @ $_{3} \mathrm{~N}_{4}$ NRs with 1T-MoS $\mathrm{MD}_{2}$ QDading of $0.5 \mathrm{wt} \%, 1.0 \mathrm{wt} \%, 3.0 \mathrm{wt} \%$ and $7.0 \mathrm{wt} \%$, were obtained by adjusting the volume of the $1 \mathrm{~T}-\mathrm{MoS}_{2}$ QD solution as 5, 10, 30 and $70 \mathrm{~mL}$, respectively.

\subsection{Characterization}

The synthesized products were characterized by X-ray diffraction (XRD, D/Max 2500PC Rigaku, Japan) utilizing a Cu K $\alpha(\lambda=1.5418 \AA)$ radiation source operated at $40 \mathrm{kV}$ at a scan rate of $4^{\circ} \mathrm{min}^{-1}$. The nanostructure and surface characteristics of the products were studied on a high-resolution scanning electron microscope (FESEM, FEI Nova Nanosem 450, USA). The morphology and crystal structure of the samples were characterized by transmission electron microscopy (TEM) and high resolution TEM (HRTEM) (JEOL JEM 2100F) with an accelerating voltage of $200 \mathrm{kV}$, and their composition was examined using energy-dispersive X-ray spectroscopy (EDS) attached to the TEM instrument. X-ray photoelectron spectroscopy (XPS) was carried out with a Thermo ESCALAB 250XI spectrometer using $\mathrm{Al} \mathrm{K} \alpha$ radiation at a voltage of $1486.6 \mathrm{eV}$ and calibrated with the $\mathrm{C} 1 \mathrm{~s}$ binding energy of $284.8 \mathrm{eV}$. The XPS results were deconvoluted with XPSPEAK software. The UV-vis-NIR diffuse reflectance spectra (DRS) of the samples were recorded on a UV-vis-NIR spectrophotometer (Hitachi UV-3101) with an integrating sphere attachment within the 200-2000 nm range and with $\mathrm{BaSO}_{4}$ as the reflectance standard. The Brunauer-Emmett-Teller (BET) specific surface area measurements were carried out by $\mathrm{N}_{2}$ adsorption at $77 \mathrm{~K}$ using a Micromeritics ASAP2020 nitrogen adsorption-desorption apparatus with prior out gassing of the sample overnight at $120{ }^{\circ} \mathrm{C}$ under a primary vacuum. Raman spectra were measured with solid samples using a HORIBA LabRAM HR Evolution Raman microscope. Transient photoluminescence curves of the as-prepared samples were obtained on a FLS980 Series fluorescence lifetime spectrophotometer. 


\subsection{Photoelectrochemical measurements}

The photocurrent response and electrochemical impedance of the samples were tested by using an electrochemical workstation (Shanghai Chenhua CHI660D) in a three-electrode system, in which the sample electrode was used as the photocathode, $\mathrm{Ag} / \mathrm{AgCl}$ as the reference electrode, a $\mathrm{Pt}$ wire as the counter electrode, and $0.5 \mathrm{M} \mathrm{Na}_{2} \mathrm{SO}_{4}$ aqueous solution as the electrolyte. The working electrodes were prepared as follows: $5 \mathrm{mg}$ of the photocatalyst (1T-MoS $\mathrm{M}_{2} @ \mathrm{C}_{3} \mathrm{~N}_{4}$ NRs composites) and $1 \mathrm{mg}$ of ethyl cellulose were dispersed into a solution containing $250 \mu \mathrm{L}$ of ethanol and $250 \mu \mathrm{L}$ of terpineol by $60 \mathrm{~min}$ sonication to prepare a homogeneous slurry. Then, $250 \mu \mathrm{L}$ of the slurry was dropped onto pretreated stannic oxide (FTO) conductive glass with an exposed area of $4.0 \mathrm{~cm}^{2}(2 \mathrm{~cm} \times 2 \mathrm{~cm})$. A $500 \mathrm{~W}$ Xe arc lamp equipped with an AM-1.5 filter was adopted as the light source.

\subsection{Photocatalytic $\mathrm{H}_{2}$ evolution}

Photocatalytic $\mathrm{H}_{2}$ production experiments were carried out in an outer irradiation type photoreactor (100 mL quartz glass) in a $\mathrm{N}_{2}$ environment. $20 \mathrm{mg}$ of the 1T- $\mathrm{MoS}_{2} @ \mathrm{C}_{3} \mathrm{~N}_{4} \mathrm{NR}$ composite photocatalyst was dispersed with mechanical stirring in $100 \mathrm{~mL}$ of an aqueous solution containing $20 \mathrm{vol} \%$ triethanolamine for further photocatalytic $\mathrm{H}_{2}$ production experiments. Before irradiation, the photocatalytic system was thoroughly degassed to remove air by bubbling $\mathrm{N}_{2}$ for $20 \mathrm{~min}$. The irradiation light source used in this study was a $300 \mathrm{~W}$ Xe arc lamp (CELHXF300, Beijing China Education Au-light Co., Ltd), which was equipped with an AM-1.5 filter. The evolved gas was analyzed using a gas chromatograph (Techcomp GC-7920) equipped with a thermal conductivity detector (TCD). The apparent quantum efficiency (AQE) was measured under similar photocatalytic reaction conditions except that a $300 \mathrm{~W}$ Xe arc lamp with an AM-1.5 filter was used as the light source. The focused intensity for the $300 \mathrm{~W}$ Xe arc lamp with the AM-1.5 filter was ca. $4601.7 \mathrm{~W} \mathrm{~m}^{-2}$. The apparent quantum efficiency (AQE) was measured and calculated according to the equation:

$$
\begin{aligned}
\mathrm{AQE} & =\frac{\text { number of reacted electrons }}{\text { number of incident photons }} \times 100 \\
& =\frac{\text { number of evolved } \mathrm{H}_{2} \text { molecules } \times 2}{\text { number of incident photons }} \times 100 \%
\end{aligned}
$$

\section{Results and discussion}

Firstly, the $\mathrm{C}_{3} \mathrm{~N}_{4}$ NRs were prepared by solvothermally treating cyanuric chloride and melamine in acetonitrile solution at $180{ }^{\circ} \mathrm{C}$ for $96 \mathrm{~h}$. Under these conditions, the $\mathrm{C}_{3} \mathrm{~N}_{4}$ frameworks could be formed due to the condensation of triazine tectons from cyanuric chloride and melamine, accompanied by the release of $\mathrm{NH}_{4} \mathrm{Cl}$ (Scheme 1). Then, 1T- $\mathrm{MoS}_{2}$ QDs were fabricated by a simple hydrothermal method (Scheme 2). The obtained 1T-MoS 2 QDs not only act as electron acceptors with high electrical conductivity, but also offer abundant reaction sites for $\mathrm{H}_{2}$ evolution. Ultimately, 1T- $\mathrm{MoS}_{2} @ \mathrm{C}_{3} \mathrm{~N}_{4} \mathrm{NR}$ composite photocatalysts were prepared via ultrasonic mixing; in this process, 1T-MoS 2 QDs were perfectly decorated on the surface of

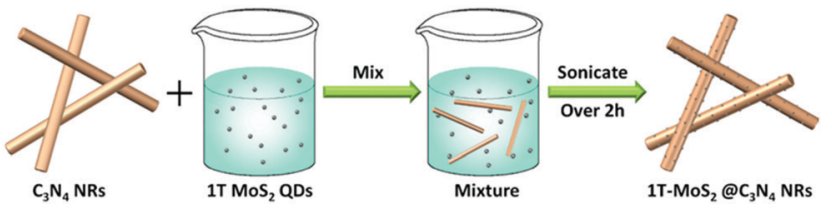

Scheme 3 Schematic illustration for the formation of $1 T-M_{0} S_{2} \mathrm{aC}_{3} \mathrm{~N}_{4} \mathrm{NR}$ composites.

$\mathrm{C}_{3} \mathrm{~N}_{4}$ NRs and offer dense active sites containing catalytically active edges and basal planes, just as schematically shown in Scheme 3.

The phases of $\mathrm{C}_{3} \mathrm{~N}_{4}$ NRs and $1 \mathrm{~T}-\mathrm{MoS}_{2} @ \mathrm{C}_{3} \mathrm{~N}_{4}$ NR composites with varying loadings of $1 \mathrm{~T}-\mathrm{MoS}_{2}$ QDs $(0.5,1.0,3.0,5.0$ and $7.0 \mathrm{wt} \%$ ) were investigated by the X-ray diffraction (XRD) patterns (Fig. 1). For comparison, $\mathrm{g}-\mathrm{C}_{3} \mathrm{~N}_{4}$ was obtained by the thermal polymerization of urea. As shown in Fig. $\mathrm{S} 1$ (ESI $\dagger$ ), g- $\mathrm{C}_{3} \mathrm{~N}_{4}$ exhibits two peaks located at $13.0^{\circ}$ and $27.5^{\circ}$, which can be well indexed to the (100) and (002) planes of $\mathrm{g}-\mathrm{C}_{3} \mathrm{~N}_{4}$, respectively. ${ }^{40,41} \mathrm{Com}$ pared with $\mathrm{g}-\mathrm{C}_{3} \mathrm{~N}_{4}, \mathrm{C}_{3} \mathrm{~N}_{4}$ NRs only display one characteristic diffraction peak located at $27.5^{\circ}$, which corresponds to the (002) plane of $\mathrm{g}-\mathrm{C}_{3} \mathrm{~N}_{4}$ due to the interlayer stacking of the conjugated aromatic systems. ${ }^{42}$ After 1T- $\mathrm{MoS}_{2}$ QD decoration, all 1T-MoS $\mathrm{M}_{2}$ $\mathrm{C}_{3} \mathrm{~N}_{4}$ NR samples exhibit similar diffraction patterns and show no XRD peak shift compared to pure $\mathrm{C}_{3} \mathrm{~N}_{4}$ NRs. This indicates that the $\mathrm{C}_{3} \mathrm{~N}_{4} \mathrm{NR}$ is the basic structure of the obtained samples, and its structure does not change after $1 \mathrm{~T}-\mathrm{MoS}_{2}$ QD loading. ${ }^{42}$ It is obvious that no diffraction peaks of $1 \mathrm{~T}-\mathrm{MoS}_{2}$ QDs can be observed even for 1T-MoS $\mathrm{S}_{2} @ \mathrm{C}_{3} \mathrm{~N}_{4} \mathrm{NRs}(7.0 \mathrm{wt} \%)$ due to the low concentration and/or low crystallinity of $1 \mathrm{~T}-\mathrm{MoS}_{2}$ in the composites. ${ }^{43,44}$

The elemental composition and chemical status of 1T-MoS $@$ $\mathrm{C}_{3} \mathrm{~N}_{4}$ NR composites were further investigated by X-ray photoelectron spectroscopy (XPS). The XPS survey spectrum (Fig. S2, $\mathrm{ESI} \dagger$ ) indicates that the $1 \mathrm{~T}-\mathrm{MoS}_{2} @ \mathrm{C}_{3} \mathrm{~N}_{4} \mathrm{NR}$ composites are composed of $\mathrm{C}, \mathrm{N}, \mathrm{Mo}$ and $\mathrm{S}$ elements. In addition, the $\mathrm{O} 1 \mathrm{~s}$ peak can also be found, due to the surface absorption and oxidation during the preparation process. ${ }^{45}$ To further analyze the 1T- $\mathrm{MoS}_{2} @ \mathrm{C}_{3} \mathrm{~N}_{4}$ NR composites, the high-resolution spectra for $\mathrm{C} 1 \mathrm{~s}, \mathrm{~N} 1 \mathrm{~s}$ Mo $3 \mathrm{~d}$ and $\mathrm{S} 2 \mathrm{p}$ of the $1 \mathrm{~T}-\mathrm{MoS}_{2} @ \mathrm{C}_{3} \mathrm{~N}_{4} \mathrm{NR}$

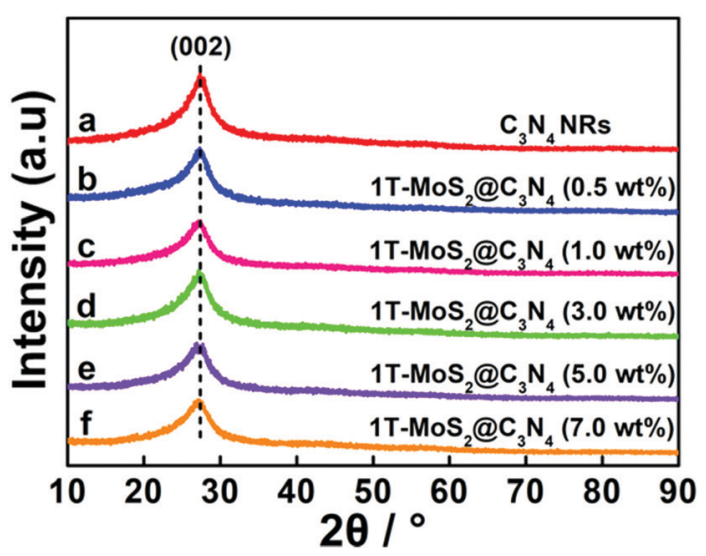

Fig. 1 XRD patterns of $\mathrm{C}_{3} \mathrm{~N}_{4}$ NRs and $1 \mathrm{~T}-\mathrm{MoS}_{2} \mathrm{aC}_{3} \mathrm{~N}_{4}$ NR composites containing different amounts of $1 \mathrm{~T}-\mathrm{MoS}_{2}$ QDs $(0.5,1.0,3.0,5.0$ and $7.0 \mathrm{wt} \%)$. 

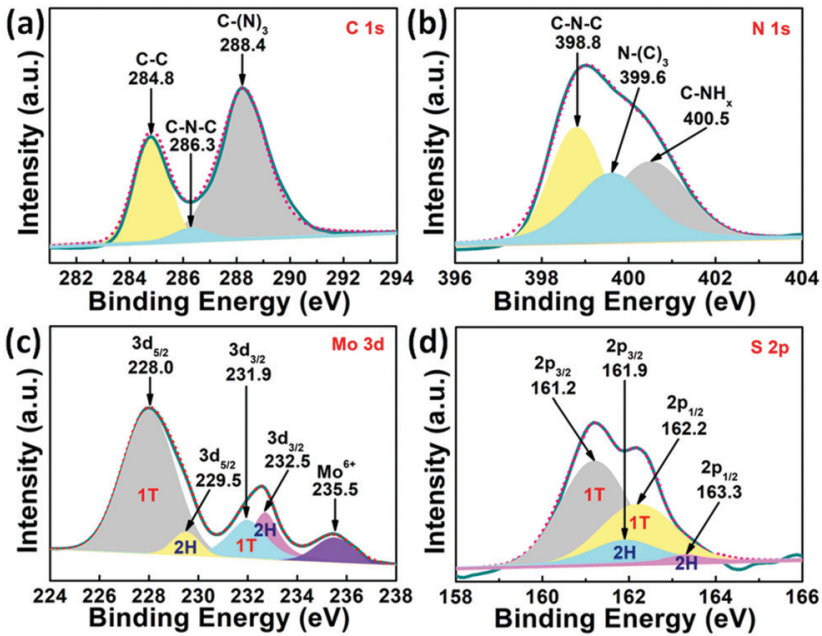

Fig. 2 High-resolution peak-fitting XPS spectra of (a) C 1s, (b) N 1s, (c) Mo $3 \mathrm{~d}$ and (d) S 2p of $1 \mathrm{~T}-\mathrm{MoS}_{2} \mathrm{aC}_{3} \mathrm{~N}_{4}$ NR composites (5.0 wt\%).

composites are depicted (Fig. 2). The C 1s spectrum (Fig. 2a) of the samples shows three peaks at $284.8,286.3$ and $288.4 \mathrm{eV}$, which can be attributed to the carbon nitride matrix group $(\mathrm{C}-\mathrm{C})$, the $\mathrm{sp}^{2}$-hybridized carbon atoms bonded to nitrogen atom in the aromatic ring group $(\mathrm{C}-\mathrm{N}-\mathrm{C})$ and the $\mathrm{sp}^{2}$-hybridized carbon atoms bonded to three nitrogen atoms in the aromatic ring attached to the $\mathrm{NH}_{2}$ group $\left(\mathrm{C}-(\mathrm{N})_{3}\right)$, respectively. ${ }^{46,47}$ The $\mathrm{N} 1 \mathrm{~s}$ spectrum (Fig. 2b) can be fitted into three peaks at 398.8, 399.6 and $400.5 \mathrm{eV}$, which arise from the $\mathrm{sp}^{2}$-hybridized nitrogen atom $(\mathrm{C}-\mathrm{N}-\mathrm{C}), \mathrm{sp}^{3}$-hybridized nitrogen atom $\left(\mathrm{N}-(\mathrm{C})_{3}\right)$ and amino groups carrying hydrogen $\left(\mathrm{C}-\mathrm{NH}_{x}\right)$, respectively. ${ }^{16,48}$ To better illustrate the existence of $1 \mathrm{~T}-\mathrm{MoS}_{2}$, the Mo $3 \mathrm{~d}$ and S 2p XPS spectra of the 1T- $\mathrm{MoS}_{2} @ \mathrm{C}_{3} \mathrm{~N}_{4}$ NR composites are given in Fig. 2c and $\mathrm{d}$. The Mo 3d spectrum (Fig. 2c) can be resolved into five

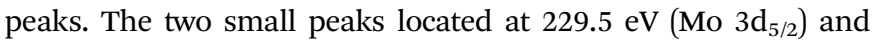

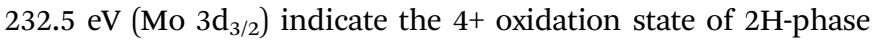
$\mathrm{MoS}_{2}$, and the main peaks at 228.0 and $231.9 \mathrm{eV}$ suggest the formation of 1T-phase $\mathrm{MoS}_{2}{ }^{49,50}$ The peak located at $235.5 \mathrm{eV}$ was assigned to $\mathrm{Mo}^{6+}$, probably owing to the oxidation of 1T-MoS $\mathrm{M}_{2} @ \mathrm{C}_{3} \mathrm{~N}_{4}$ NRs by the exposure to air. Fig. 2d shows the $\mathrm{S}$ $2 \mathrm{p}$ spectrum, in which the main two peaks at $161.2 \mathrm{eV}\left(\mathrm{S} 2 \mathrm{p}_{3 / 2}\right)$ and $162.2 \mathrm{eV}\left(\mathrm{S} 2 \mathrm{p}_{1 / 2}\right)$ represent the 1T-phase $\mathrm{MoS}_{2}$, and the two small peaks at $161.9 \mathrm{eV}\left(\mathrm{S} \mathrm{2} \mathrm{p}_{3 / 2}\right)$ and $163.3 \mathrm{eV}\left(\mathrm{S} \mathrm{2} \mathrm{p}_{1 / 2}\right)$ indicate the 2H-phase $\mathrm{MoS}_{2} \cdot{ }^{49,50}$ The concentration of the $1 \mathrm{~T}$ phase in the $1 \mathrm{~T}-\mathrm{MoS}_{2} @ \mathrm{C}_{3} \mathrm{~N}_{4}$ NR composites is approximately calculated to be $\sim 79 \%$, which indicates the predominance of the $1 \mathrm{~T}$ phase over its $2 \mathrm{H}$ counterpart. The above results further confirm the existence of $\mathrm{C}_{3} \mathrm{~N}_{4}$ and 1T- $\mathrm{MoS}_{2}$ in 1T- $\mathrm{MoS}_{2} @ \mathrm{C}_{3} \mathrm{~N}_{4}$ NR samples. The vibrational properties of the prepared $\mathrm{C}_{3} \mathrm{~N}_{4} \mathrm{NRs}$ and $1 \mathrm{~T}-\mathrm{MoS}_{2} @ \mathrm{C}_{3} \mathrm{~N}_{4} \mathrm{NR}$ composites (5.0 wt $\%$ ) were determined by Raman spectroscopy. As can be seen in Fig. S3 (ESI $\dagger$ ), the band at $978 \mathrm{~cm}^{-1}$ corresponds to the stretching vibration of the $\mathrm{CN}$ heterocycle in the $\mathrm{g}-\mathrm{C}_{3} \mathrm{~N}_{4}$ structure. ${ }^{51}$ The band at $740 \mathrm{~cm}^{-1}$ is also ascribed to g- $\mathrm{C}_{3} \mathrm{~N}_{4}$, which appears in both spectra. No peaks ascribed to $1 \mathrm{~T}-\mathrm{MoS}_{2}$ QDs can be detected in the 1T-MoS $@ \mathrm{C}_{3} \mathrm{~N}_{4}$ NRs (5.0 wt\%), due to the low content of $\mathrm{MoS}_{2}$ in the hybrid. This result is consistent with the XRD data as shown in Fig. 1.
The morphology and size of $\mathrm{C}_{3} \mathrm{~N}_{4} \mathrm{NRs}$ and 1T-MoS $\mathrm{MC}_{3} \mathrm{~N}_{4}$ NR composites were investigated by scanning electron microscopy (SEM). Obviously, the $\mathrm{C}_{3} \mathrm{~N}_{4}$ sample exhibits a rod-like structure with a length of 300-500 nm (Fig. 3a). Subsequently, the surface decoration of $\mathrm{C}_{3} \mathrm{~N}_{4}$ NRs with 1T-MoS $\mathrm{M}_{2}$ QDs was carried out by sonication of the $\mathrm{C}_{3} \mathrm{~N}_{4}$ NRs in an aqueous solution of $1 \mathrm{~T}-\mathrm{MoS}_{2}$ QDs for over $2 \mathrm{~h}$. In this process, $1 \mathrm{~T}-\mathrm{MoS}_{2}$ QDs could be absorbed on the surface of $\mathrm{C}_{3} \mathrm{~N}_{4}$ NRs, resulting in the assembly of $1 \mathrm{~T}-\mathrm{MoS}_{2}$ QDs on $\mathrm{C}_{3} \mathrm{~N}_{4}$ NRs (Scheme 3). The obtained 1T- $\mathrm{MoS}_{2} @ \mathrm{C}_{3} \mathrm{~N}_{4}$ NR composites still retained the rodshaped structure (Fig. 3b). 1T-MoS 2 QDs were difficult to discern through SEM due to their very small size.

In order to further visualize the morphology and microstructure of the as-prepared pure 1T- $\mathrm{MoS}_{2}$ QDs and 1T- $\mathrm{MoS}_{2}$ @ $\mathrm{C}_{3} \mathrm{~N}_{4}$ NR composites, TEM images were employed (Fig. 4 and 5). Obviously, Fig. 4a reveals that pure 1T- $\mathrm{MoS}_{2}$ QDs are distributed homogeneously without apparent aggregation, which possess well-dispersed ultrasmall particles of size about 2-3 nm. From the HRTEM image (Fig. 4b) of $1 \mathrm{~T}-\mathrm{MoS}_{2}$ QDs, no typical (002) lattice plane of crystalline $\mathrm{MoS}_{2}$ is observed, indicating that $1 \mathrm{~T}-\mathrm{MoS}_{2}$ QDs contain only a single layer or very few layers. ${ }^{52}$ The atomic force microscopy (AFM) image shown in Fig. S4 (ESI $\dagger$ ) also confirms the formation of the $1 \mathrm{~T}-\mathrm{MoS}_{2}$ QDs with good dispersion. Furthermore, the 1T-phase $\mathrm{MoS}_{2}$ can be clearly visualized (inset in Fig. 4b), evidently displaying the trigonal lattice areas (octahedral coordination) of the $1 \mathrm{~T}$ phase of $\mathrm{MoS}_{2}$ QDs. ${ }^{50,53}$ As displayed in Fig. 5a, the 1T- $\mathrm{MoS}_{2} @ \mathrm{C}_{3} \mathrm{~N}_{4}$ NR composites exhibit a 1D rod-shaped morphology. However, plenty of black dot-like structures (the regions enclosed by the red circles) are seen decorating the nanorod with a diameter of several nanometers (Fig. 5b). A closer inspection of the TEM image

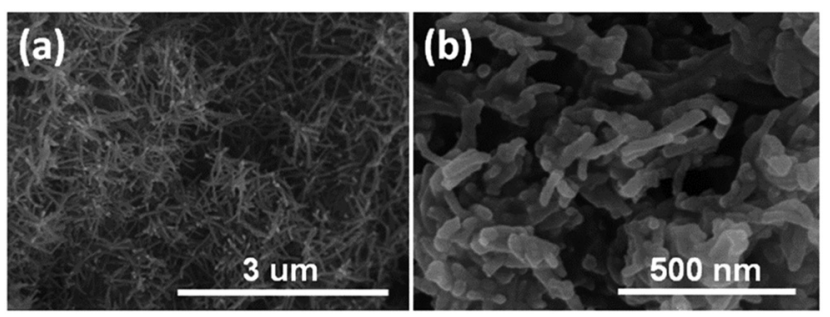

Fig. 3 SEM images of (a) $\mathrm{C}_{3} \mathrm{~N}_{4}$ NRs and (b) $1 \mathrm{~T}-\mathrm{MoS}_{2}\left(\mathrm{CC}_{3} \mathrm{~N}_{4}\right.$ NR composites (5.0 wt\%).

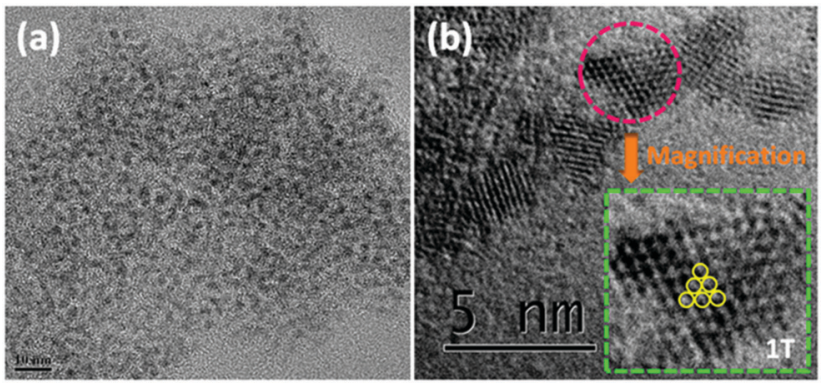

Fig. 4 (a) TEM images and (b) HRTEM image of $1 T-M_{2} S_{2}$ QDs (the inset shows the magnification of the region enclosed by the pink circle). 

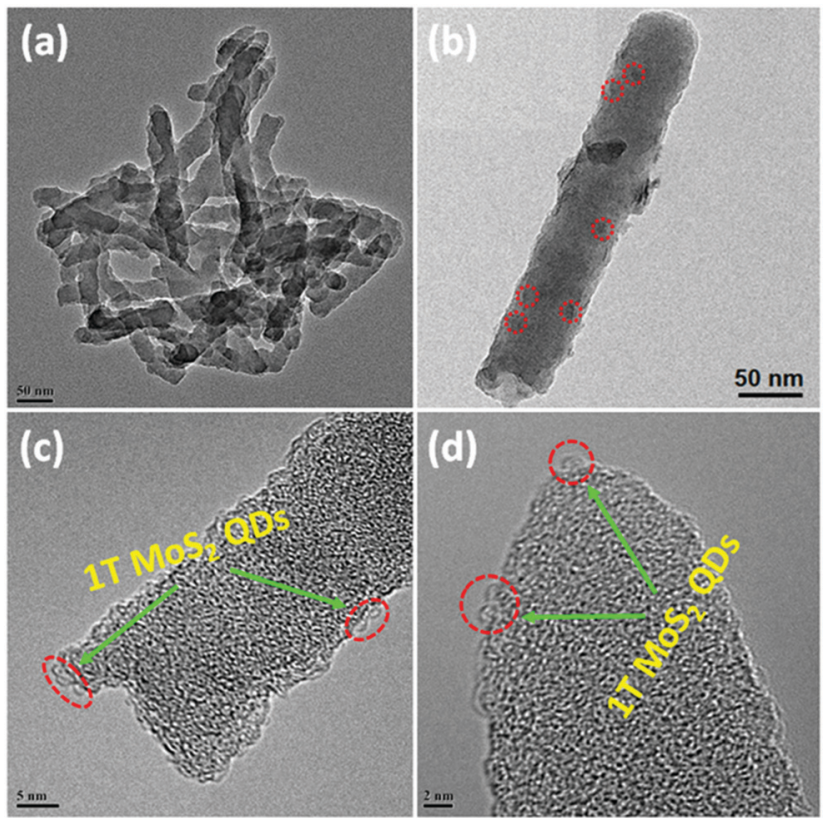

Fig. 5 TEM image of $1 T-M_{0}{ }_{2}\left(\mathrm{CC}_{3} \mathrm{~N}_{4}\right.$ NR composites (5.0 wt\%).

(Fig. 5c and d) indicates that these nanodots (1T-MoS 2 QDs) are closely attached on the surface of the nanorod. Such a heterostructure with close contact interfaces ensures the fast separation and transfer of charge carriers across the interfaces. Moreover, the EDS mapping (Fig. 6) analysis of $1 \mathrm{~T}-\mathrm{MoS}_{2} @ \mathrm{C}_{3} \mathrm{~N}_{4}$ NR composites displays the uniform distribution of $\mathrm{C}, \mathrm{N}, \mathrm{Mo}$ and $\mathrm{S}$, further confirming that $1 \mathrm{~T}-\mathrm{MoS}_{2}$ QDs are successfully loaded on the surface of $\mathrm{C}_{3} \mathrm{~N}_{4}$ NRs.

To determine the surface area of the as-synthesized samples, the $\mathrm{N}_{2}$ adsorption-desorption isotherms were measured for the samples. The nitrogen adsorption-desorption isotherms and the corresponding pore size distribution curves of the samples are shown in Fig. S5 (ESI $\dagger$ ), and the specific surface areas of the samples are listed in Table S1 (ESI $\dagger$ ). The $\mathrm{N}_{2}$ adsorptiondesorption isotherms of all the samples are typical Langmuir type IV isotherms with a typical $\mathrm{H}_{3}$ hysteresis loop at high pressure, indicating the presence of mesopores in all samples. ${ }^{54,55}$ The pore size distribution curves (Fig. S5b-f, ESI $†$ inset) reveal that the pore size diameter of the 1T-MoS $@ \mathrm{C}_{3} \mathrm{~N}_{4} \mathrm{NR}$ composites is about $2 \mathrm{~nm}$, while the pore size diameter of pure $\mathrm{C}_{3} \mathrm{~N}_{4}$ NRs is about $4 \mathrm{~nm}$ (Fig. S5a, ESI $\dagger$ inset). Besides, the results show that the 1T-MoS $@$ $\mathrm{C}_{3} \mathrm{~N}_{4}$ NR composites containing different amounts of $1 \mathrm{~T}-\mathrm{MoS}_{2}$ QDs have similar specific surface areas (Table S1, ESI $\dagger$ ). Thus, the effect of the BET surface area on the hydrogen evolution activity of the 1T-MoS $\mathrm{M}_{2} @ \mathrm{C}_{3} \mathrm{~N}_{4}$ NR composites is uncertain in this work.

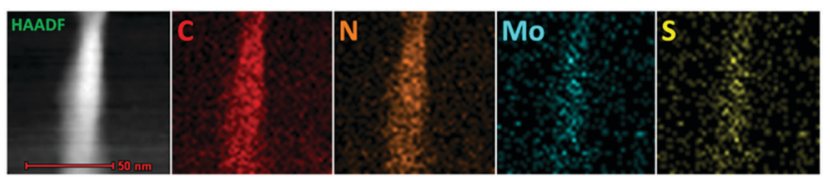

Fig. 6 Selected HAADF image and corresponding EDS elemental mappings of $1 \mathrm{~T}-\mathrm{MoS}_{2} \mathrm{aC}_{3} \mathrm{~N}_{4}$ NR composites (5.0 wt\%).
The optical properties of the samples were measured by UV-vis-NIR diffuse reflectance spectroscopy (DRS) (Fig. 7 and Fig. S6a, ESI $\dagger$ ). As shown in Fig. S6a (ESI $\dagger$ ), g- $\mathrm{C}_{3} \mathrm{~N}_{4}$ nanosheets exhibit a short-wavelength absorption with an edge at $\sim 470 \mathrm{~nm}$. For the $\mathrm{C}_{3} \mathrm{~N}_{4}$ NR sample, it exhibits a wide photoabsorption range from the UV to visible region with an absorption edge at $\sim 754 \mathrm{~nm}$, indicating a large redshift compared with that of pure $\mathrm{g}-\mathrm{C}_{3} \mathrm{~N}_{4}(\sim 470 \mathrm{~nm})$. The UV-vis-NIR absorption spectrum of $1 \mathrm{~T}-\mathrm{MoS}_{2}$ QDs gives a smooth line without any obvious absorption band (Fig. S7, ESI $\dagger$ ), confirming the metallic characteristics of $1 \mathrm{~T}-\mathrm{MoS}_{2}$ QDs. Furthermore, it is obvious that loading the 1T- $\mathrm{MoS}_{2}$ QD co-catalysts onto the surface of $\mathrm{C}_{3} \mathrm{~N}_{4}$ NRs can broaden the absorption range to the NIR light region (Fig. 7). Importantly, the 1T- $\mathrm{MoS}_{2} @ \mathrm{C}_{3} \mathrm{~N}_{4} \mathrm{NR}$ composites (5.0 wt\%) display stronger optical absorption with an edge at $\sim 850 \mathrm{~nm}$, indicating a large red-shift compared with that of $\mathrm{C}_{3} \mathrm{~N}_{4}$ NRs and 1T-MoS $\mathrm{MoC}_{2} \mathrm{~N}_{4} \mathrm{NR}$ composites containing other amounts of $1 \mathrm{~T}-\mathrm{MoS}_{2}$ QDs $(0.5,1.0,3.0$ and $7.0 \mathrm{wt} \%)$. Thus, the enhanced light absorption of $1 \mathrm{~T}-\mathrm{MoS}_{2} @ \mathrm{C}_{3} \mathrm{~N}_{4}$ NR composites is favorable to produce more photo-generated electrons and holes, which is in turn beneficial to the photocatalytic HER activity. ${ }^{56}$ Furthermore, the band gap energy of g- $\mathrm{C}_{3} \mathrm{~N}_{4}$ and $\mathrm{C}_{3} \mathrm{~N}_{4}$ NRs could be computed from the formula $(\alpha \mathrm{h} \nu)^{1 / 2} \propto h \nu-E_{\mathrm{g}}$, where $\alpha, h, \nu$, and $E_{\mathrm{g}}$ are the absorption coefficient, Planck's constant, light frequency, and band gap energy, respectively. Then the estimated $E_{\mathrm{g}}$ of $\mathrm{g}-\mathrm{C}_{3} \mathrm{~N}_{4}$ and $\mathrm{C}_{3} \mathrm{~N}_{4}$ NRs is 2.47 and $1.38 \mathrm{eV}$, respectively (Fig. S6b, ESI $\dagger$ ).

We further tested the photoexcited charge carrier lifetimes of pure $\mathrm{C}_{3} \mathrm{~N}_{4}$ NRs and 1T-MoS ${ }_{2} @ \mathrm{C}_{3} \mathrm{~N}_{4}$ NR composites by using time-resolved fluorescence decay spectroscopy. As shown in Fig. 8, by fitting the fluorescence lifetime decay curve, we conclude that both pure $\mathrm{C}_{3} \mathrm{~N}_{4}$ NRs and 1T-MoS $@ \mathrm{C}_{3} \mathrm{~N}_{4}$ NR composites show single exponential decay. The intensity-average lifetime $(\tau)$ of pure $\mathrm{C}_{3} \mathrm{~N}_{4} \mathrm{NRs}$ is $0.1545 \mathrm{~ns}$, which is lower than that of the $1 \mathrm{~T}-\mathrm{MoS}_{2} @ \mathrm{C}_{3} \mathrm{~N}_{4}$ NR composites (0.3585 ns). The extension of the trapped carrier lifetimes in 1T- $\mathrm{MoS}_{2} @ \mathrm{C}_{3} \mathrm{~N}_{4} \mathrm{NR}$ composites indicates the advantages of surface decoration of $\mathrm{C}_{3} \mathrm{~N}_{4}$ NRs by $1 \mathrm{~T}-\mathrm{MoS}_{2}$ QDs, which promotes electron-hole separation and hinders their efficient recombination.

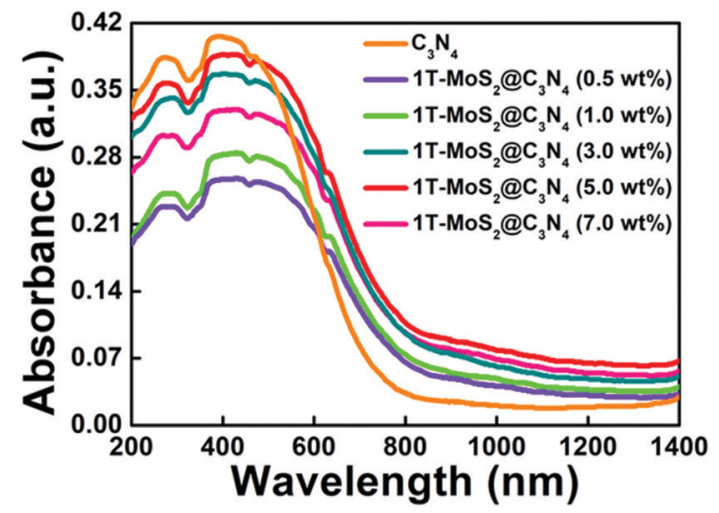

Fig. 7 UV-vis-NIR light absorption spectra of $\mathrm{C}_{3} \mathrm{~N}_{4}$ NRs and $1 \mathrm{~T}-\mathrm{MoS}_{2} \mathrm{a}$ $\mathrm{C}_{3} \mathrm{~N}_{4} \mathrm{NR}$ composites containing different amounts of $1 \mathrm{~T}-\mathrm{MoS}_{2}$ QDs $(0.5,1.0,3.0,5.0$ and $7.0 \mathrm{wt} \%)$. 


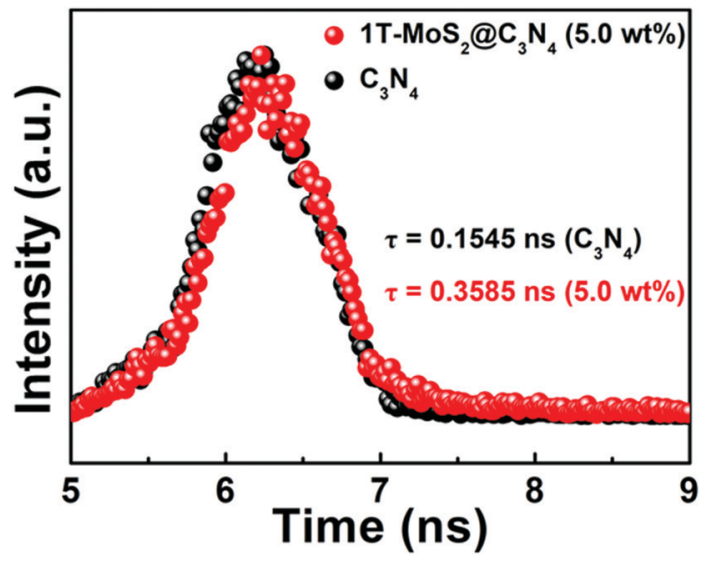

Fig. 8 Luminescence decay curves of pure $\mathrm{C}_{3} \mathrm{~N}_{4} \mathrm{NRs}$ and $1 \mathrm{~T}-\mathrm{MoS}_{2} \mathrm{aC}_{3} \mathrm{~N}_{4}$ NR composites (5.0 wt\%).

To gain deep insights into the charge transfer behaviors in the 1T-MoS ${ }_{2} @ \mathrm{C}_{3} \mathrm{~N}_{4}$ NR composites, the photocurrent responses were studied and electrochemical impedance spectroscopy (EIS) was carried out. Fig. 9a shows the periodic on/off photocurrent response of all samples when irradiated under solar light. It can be seen that all the samples show an immediate rise in the photocurrent response when the light is on. In contrast, the photocurrent rapidly decreases to zero when the light is turned off. The on-off cycles of photocurrent are reproducible, which indicates that the photogenerated electrons are transferred to the back contact across the samples to form the photocurrent under light irradiation. ${ }^{57}$ The pure $\mathrm{C}_{3} \mathrm{~N}_{4} \mathrm{NR}$ electrode generates a relatively low photocurrent density of $0.019 \mu \mathrm{A} \mathrm{cm}^{-2}$. The photocurrent response curves (Fig. 9a) show an increased current density in all 1T- $\mathrm{MoS}_{2} @ \mathrm{C}_{3} \mathrm{~N}_{4} \mathrm{NR}$ samples as compared with pure $\mathrm{C}_{3} \mathrm{~N}_{4}$ NRs, indicating a noticeable improvement of the electron-hole separation efficiency by the introduction of $1 \mathrm{~T} \mathrm{MoS}_{2}$ QD co-catalysts. ${ }^{56}$ The 1T-MoS $\mathrm{MOC}_{3} \mathrm{~N}_{4}$ NR composite (5.0 wt\%) electrode shows the highest photocurrent density of $0.108 \mu \mathrm{A} \mathrm{cm}{ }^{-2}$, which is about 5.7 times higher than that of a bare $\mathrm{C}_{3} \mathrm{~N}_{4}$ NR electrode. On the one hand, $1 \mathrm{~T}-\mathrm{MoS}_{2} @ \mathrm{C}_{3} \mathrm{~N}_{4} \mathrm{NR}$ composites (5.0 wt $\%$ ) have a wider absorption range and stronger photoabsorption ability, resulting in more photogenerated carriers. On the other hand, 1T-MoS 2 QDs can act as electron acceptors to capture photo-generated electrons before they recombine with holes, leading to more effective separation of electron-hole pairs. The EIS measurement is also an effective approach to study the charge transfer process. In general, a smaller arc radius on an EIS Nyquist plot means a
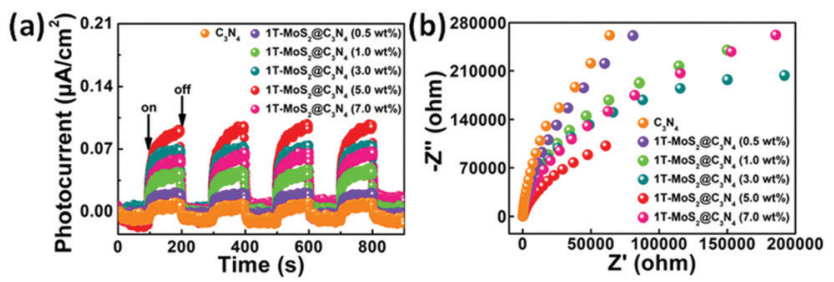

Fig. 9 (a) The transient photocurrent responses and (b) the electrochemical impedance spectra (EIS) of the samples under solar light irradiation. smaller charge-transfer resistance on the electrode surface and a higher separation efficiency of electron-hole pairs. ${ }^{58}$ As illustrated in Fig. 9b, the order of arc size for the samples under solar light irradiation is $1 \mathrm{~T}-\mathrm{MoS}_{2} @ \mathrm{C}_{3} \mathrm{~N}_{4} \mathrm{NR}$ composites $(5.0 \mathrm{wt} \%)<1 \mathrm{~T}$ $\mathrm{MoS}_{2} @ \mathrm{C}_{3} \mathrm{~N}_{4} \mathrm{NR}$ composites (3.0wt\%) < 1T- $\mathrm{MoS}_{2} @ \mathrm{C}_{3} \mathrm{~N}_{4} \mathrm{NR}$ composites (7.0 wt\%) $<1 \mathrm{~T}-\mathrm{MoS}_{2} @ \mathrm{C}_{3} \mathrm{~N}_{4}$ NR composites $(1.0 \mathrm{wt} \%)<1 \mathrm{~T}-\mathrm{MoS}_{2} @ \mathrm{C}_{3} \mathrm{~N}_{4} \mathrm{NR}$ composites $(0.5 \mathrm{wt} \%)<$ pure $\mathrm{C}_{3} \mathrm{~N}_{4}$ NRs, suggesting that the $1 \mathrm{~T}-\mathrm{MoS}_{2} @ \mathrm{C}_{3} \mathrm{~N}_{4}$ NR composites (5.0 wt\%) display the most effective separation of photogenerated charges. Apparently, this is in good agreement with luminescence decay and photocurrent results, validating that the $1 \mathrm{~T}-\mathrm{MoS}_{2} @ \mathrm{C}_{3} \mathrm{~N}_{4}$ NR composites would obviously improve the charge transfer rate. Note that the higher interfacial charge transfer ability of the 1T- $\mathrm{MoS}_{2} @ \mathrm{C}_{3} \mathrm{~N}_{4}$ NR composites implies that the recombination rate of electrons and holes has been reduced, thereby contributing to the enhanced photocatalytic efficiency and stability toward hydrogen production.

The photocatalytic activity for $\mathrm{H}_{2}$ evolution was evaluated under simulated sunlight irradiation using a $300 \mathrm{~W}$ Xe arc lamp with an AM-1.5 filter. Fig. 10 presents a comparison of the photocatalytic $\mathrm{H}_{2}$ production activities of $\mathrm{C}_{3} \mathrm{~N}_{4}$ NRs ( $\mathrm{Pt}$ as co-catalyst) and 1T-MoS ${ }_{2} @ \mathrm{C}_{3} \mathrm{~N}_{4} \mathrm{NR}$ composites containing different amounts of co-catalyst (0.5, 1.0, 3.0, 5.0 and $7.0 \mathrm{wt} \%$ $1 \mathrm{~T}-\mathrm{MoS}_{2}$ QDs) in aqueous solution with TEOA. It can be seen that no $\mathrm{H}_{2}$ is detected for $\mathrm{C}_{3} \mathrm{~N}_{4} \mathrm{NRs}$ in the absence of a co-catalyst (Fig. S8, ESI $\dagger$ ), which can be ascribed to their limited lightharvesting efficiency and fast recombination of photoinduced charge carriers. Notably, after the assembly of $1 \mathrm{~T}-\mathrm{MoS}_{2}$ QDs, a significantly improved photocatalytic performance was observed, with the highest photocatalytic $\mathrm{H}_{2}$ evolution rate of $565 \mu \mathrm{mol} \mathrm{h}{ }^{-1} \mathrm{~g}^{-1}$ occurring for the $5.0 \mathrm{wt} \% \mathrm{MoS}_{2}$ sample (Fig. 10). The 1T-MoS $\mathrm{MCC}_{3} \mathrm{~N}_{4}$ NR composites $(0.5,1.0$ and $3.0 \mathrm{wt} \%$ ), which are composed of a small amount of $\mathrm{MoS}_{2}$, display a lower photocatalytic performance compared with 1T-MoS $@ \mathrm{C}_{3} \mathrm{~N}_{4}$ NR composites (5.0 wt\%), because of the relatively poor light absorption (Fig. 7). Furthermore, with increasing the content of $\mathrm{MoS}_{2}$ from $5.0 \mathrm{wt} \%$ to $7.0 \mathrm{wt} \%$, a decrease in the photocatalytic activity of the 1T- $-\mathrm{MoS}_{2} @ \mathrm{C}_{3} \mathrm{~N}_{4}$ NR composites is discovered, which is due to the light-screening effect of the excessive amount of co-catalysts..$^{59,60}$

Besides, the photocatalytic $\mathrm{H}_{2}$ evolution rate of 1T-MoS $@$ $\mathrm{C}_{3} \mathrm{~N}_{4}$ NR composites (5.0 wt\%) also exceeds that of $\mathrm{Pt}_{0} \mathrm{C}_{3} \mathrm{~N}_{4}$
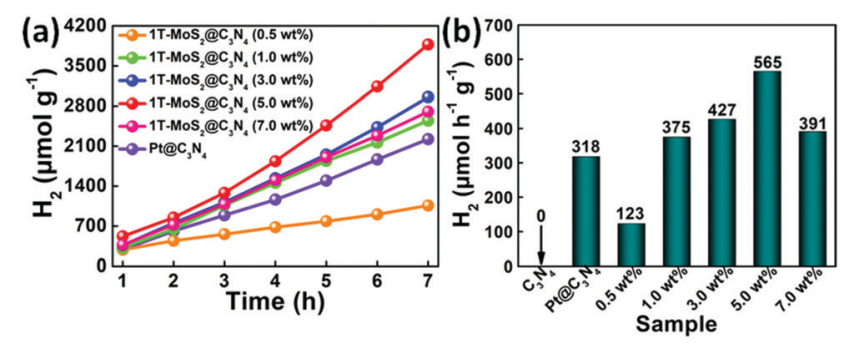

Fig. 10 (a) Cumulated evolution and (b) photocatalytic $\mathrm{H}_{2}$ evolution rate of $\mathrm{C}_{3} \mathrm{~N}_{4} \mathrm{NRs}\left(\mathrm{H}_{2} \mathrm{PtCl}_{6} \cdot 6 \mathrm{H}_{2} \mathrm{O}\right.$ as co-catalyst) and $1 \mathrm{~T}-\mathrm{MoS}_{2} \mathrm{aC}_{3} \mathrm{~N}_{4} \mathrm{NR}$ composites containing different amounts of co-catalyst $(0.5,1.0,3.0$, 5.0 and $\left.7.0 \mathrm{wt} \% 1 \mathrm{~T}-\mathrm{MOS}_{2} \mathrm{QDs}\right)$ under simulated solar light. 
NRs $\left(318 \mu \mathrm{mol} \mathrm{h} \mathrm{h}^{-1} \mathrm{~g}^{-1}\right)$. Moreover, the photocatalytic $\mathrm{H}_{2}$ production catalyzed by 1T- $\mathrm{MoS}_{2} @ \mathrm{C}_{3} \mathrm{~N}_{4}$ NR composites (5.0 wt\%) is measured under prolonged simulated solar light irradiation for $21 \mathrm{~h}$ (Fig. S9, ESI $\dagger$ ), and no obvious decay of photocatalytic HER is discerned, suggesting good durability and practical application for $1 \mathrm{~T}-\mathrm{MoS}_{2} @ \mathrm{C}_{3} \mathrm{~N}_{4} \mathrm{NR}$ composites. High-resolution peak-fitting XPS spectra of Mo $3 \mathrm{~d}$ of $1 \mathrm{~T}-\mathrm{MoS}_{2} @ \mathrm{C}_{3} \mathrm{~N}_{4}$ NR composites (5.0 wt\%) after cycling under simulated solar light irradiation are measured (Fig. S10, ESI $\dagger$ ). As shown in Fig. S10 (ESI $\dagger$ ), there is almost no change in the $\mathrm{Mo}^{6+}\left(\mathrm{MoO}_{3}\right)$ XPS peaks of the $1 \mathrm{~T}-\mathrm{MoS}_{2} @ \mathrm{C}_{3} \mathrm{~N}_{4} \mathrm{NR}$ composites (5.0 wt\%) before cycling and after cycling, which further confirms the excellent stability of the 1T-MoS ${ }_{2} @ \mathrm{C}_{3} \mathrm{~N}_{4}$ NR composites. We further evaluated the apparent quantum efficiency (AQE) of the samples under a $300 \mathrm{~W}$ Xe arc lamp with an AM-1.5 optical filter. Table S2 (ESI $\dagger$ ) shows the comparison of AQE values over $\mathrm{C}_{3} \mathrm{~N}_{4} \mathrm{NRs}, \mathrm{Pt} @ \mathrm{C}_{3} \mathrm{~N}_{4} \mathrm{NRs}$ and $1 \mathrm{~T}-\mathrm{MoS}_{2} @ \mathrm{C}_{3} \mathrm{~N}_{4}$ NR composites containing different amounts of $1 \mathrm{~T}-\mathrm{MoS}_{2}$ QDS (0.5, 1.0, 3.0, 5.0 and 7.0 wt\%): $0\left(\mathrm{C}_{3} \mathrm{~N}_{4} \mathrm{NRs}\right)<0.47 \%\left(1 \mathrm{~T}-\mathrm{MoS}_{2}\right.$ @ $\left.\mathrm{C}_{3} \mathrm{~N}_{4}-0.5 \mathrm{wt} \%\right)<0.99 \%\left(\mathrm{Pt} @ \mathrm{C}_{3} \mathrm{~N}_{4} \mathrm{NRs}\right)<1.13 \%\left(1 \mathrm{~T}-\mathrm{MoS}_{2} @\right.$ $\left.\mathrm{C}_{3} \mathrm{~N}_{4}-1.0 \mathrm{wt} \%\right)<1.21 \%\left(1 \mathrm{~T}-\mathrm{MoS}_{2} @ \mathrm{C}_{3} \mathrm{~N}_{4}-7.0 \mathrm{wt} \%\right)<1.31 \%$ $\left(1 \mathrm{~T}-\mathrm{MoS}_{2} @ \mathrm{C}_{3} \mathrm{~N}_{4}-3.0 \mathrm{wt} \%\right)<1.73 \%\left(1 \mathrm{~T}-\mathrm{MoS}_{2} @ \mathrm{C}_{3} \mathrm{~N}_{4}-5.0 \mathrm{wt} \%\right)$. Therefore, the 1T- $\mathrm{MoS}_{2} @ \mathrm{C}_{3} \mathrm{~N}_{4}$ NR composites can be used as an efficient and stable photocatalyst.

To further explore the photocatalytic mechanism of 1T-MoS $@$ $\mathrm{C}_{3} \mathrm{~N}_{4}$ NR composites, Mott-Schottky plots were recorded to evaluate the conduction band (CB) levels of $\mathrm{C}_{3} \mathrm{~N}_{4}$ NRs. As shown in Fig. S11 (ESI $\dagger$ ), by extrapolating the $x$ intercept of the linear region, the flat band potentials $\left(E_{\mathrm{FB}}\right)$ of $\mathrm{C}_{3} \mathrm{~N}_{4}$ NRs were obtained to be $-0.71 \mathrm{~V} v s$. $\mathrm{Ag} / \mathrm{AgCl}$ from the Mott-Schottky plots, corresponding to $-0.51 \mathrm{~V} v$ s. the normal hydrogen electrode (NHE). It is widely accepted that the conduction band potential $\left(E_{\mathrm{CB}}\right)$ of an n-type semiconductor is more negative by about $0.1 \mathrm{~V}$ than its $E_{\mathrm{FB}}$ value, ${ }^{61}$ therefore, the $E_{\mathrm{CB}}$ of $\mathrm{C}_{3} \mathrm{~N}_{4} \mathrm{NRs}$ could be approximated to be $-0.61 \mathrm{~V} v$ s. NHE. Combined with the $E_{\mathrm{g}}$ of $\mathrm{C}_{3} \mathrm{~N}_{4}$ NRs $(1.38 \mathrm{eV})$ obtained from the UV-vis DRS spectra (Fig. S6b, ESI $\dagger$ ), the estimated valence band potential $\left(E_{\mathrm{VB}}\right)$ of $\mathrm{C}_{3} \mathrm{~N}_{4} \mathrm{NRs}$ is $0.77 \mathrm{eV}$ vs. NHE.

Based on the above results, a possible photocatalytic HER process of $1 \mathrm{~T}-\mathrm{MoS}_{2} @ \mathrm{C}_{3} \mathrm{~N}_{4} \mathrm{NR}$ composites under simulated solar light irradiation is proposed and schematically displayed in Scheme 4. Typically, under simulated solar light irradiation, electron-hole pairs are generated in $\mathrm{C}_{3} \mathrm{~N}_{4} \mathrm{NRs}$, and then the photo-excited electrons rapidly transfer to the $1 \mathrm{~T}-\mathrm{MoS}_{2}$ QD

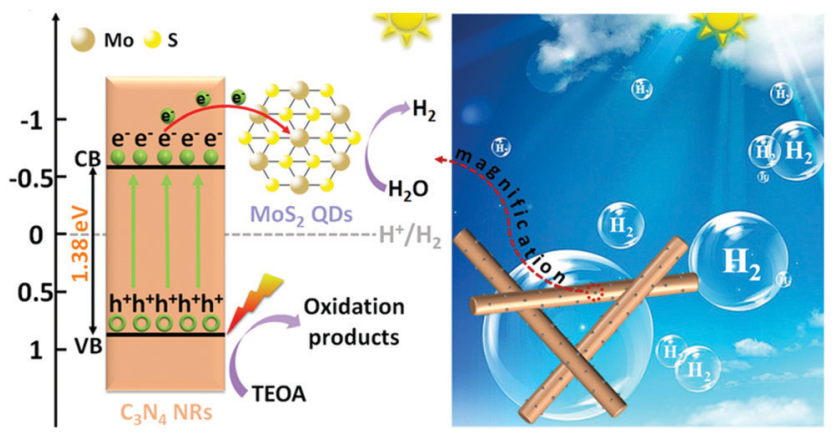

Scheme 4 Schematic illustration of the photocatalytic mechanism of $1 \mathrm{~T}-\mathrm{MoS}_{2} \mathrm{aC}_{3} \mathrm{~N}_{4}$ NR composites under simulated solar light irradiation. co-catalyst quickly, because the $1 \mathrm{~T}-\mathrm{MoS}_{2}$ QDs are good electron acceptors due to their metallic characteristics. As photoelectron acceptors, 1T- $\mathrm{MoS}_{2}$ QDs act as active sites for $\mathrm{H}_{2}$ evolution. In addition, in the 1T- $\mathrm{MoS}_{2} @ \mathrm{C}_{3} \mathrm{~N}_{4} \mathrm{NR}$ composites, small-sized $1 \mathrm{~T}-\mathrm{MoS}_{2}$ QDs well attached on the $\mathrm{C}_{3} \mathrm{~N}_{4}$ NRs enable electron transfer from $\mathrm{C}_{3} \mathrm{~N}_{4}$ NRs to $1 \mathrm{~T}-\mathrm{MoS}_{2}$ QDs in a short distance and simultaneously provide more reaction sites on both basal planes and edges for the evolution of $\mathrm{H}_{2}$. The holes would react with the sacrificial agent (TEOA) (Scheme 4). This effective electron transport between $\mathrm{C}_{3} \mathrm{~N}_{4}$ NRs and 1T- $\mathrm{MoS}_{2}$ QDs tremendously decreases the recombination of electron-hole pairs and prolong the charge lifetime.

\section{Conclusions}

$1 \mathrm{~T}-\mathrm{MoS}_{2}$ QDs were successfully synthesized and subsequently assembled with $\mathrm{C}_{3} \mathrm{~N}_{4}$ NRs as effective co-catalysts for photocatalytic $\mathrm{H}_{2}$ evolution over noble metal Pt. Specifically, an optimized 1T- $\mathrm{MoS}_{2}$ @ $\mathrm{C}_{3} \mathrm{~N}_{4} \mathrm{NR}$ composite (5.0 wt\%) attains a remarkable increased solar light photocatalytic $\mathrm{H}_{2}$ evolution rate of $565 \mu \mathrm{mol} \mathrm{h}^{-1} \mathrm{~g}^{-1}$ which is apparently higher than that of Pt@ $\mathrm{C}_{3} \mathrm{~N}_{4}$ NRs $\left(318 \mu \mathrm{mol} \mathrm{h} \mathrm{h}^{-1} \mathrm{~g}^{-1}\right)$. The highly efficient photocatalytic performance of the $1 \mathrm{~T}-\mathrm{MoS}_{2} @ \mathrm{C}_{3} \mathrm{~N}_{4} \mathrm{NR}$ composite is primarily attributed to the following facts: (1) 1T-MoS $\mathrm{SDs}_{2}$ in cooperation with $\mathrm{C}_{3} \mathrm{~N}_{4}$ NRs can enhance the light absorption intensity and broaden the light absorption range to NIR light; (2) the tiny particle size of $1 \mathrm{~T}-\mathrm{MoS}_{2} \mathrm{QD}$ co-catalysts can provide more active sites, which is helpful for the photocatalytic reaction; (3) the close contact layer between metallic 1T-MoS ${ }_{2}$ QDs and $\mathrm{C}_{3} \mathrm{~N}_{4}$ NRs is more favorable to transfer photo-generated electrons from the $\mathrm{CB}$ of $\mathrm{C}_{3} \mathrm{~N}_{4}$ to the surface of conductive 1T-MoS , and then the electrons would rapidly participate in photocatalytic HER.

\section{Conflicts of interest}

There are no conflicts to declare.

\section{Acknowledgements}

The authors are thankful for funding from the National Natural Science Foundation of China (No. 51872173), Taishan Scholarship of Young Scholars (No. tsqn201812068), Natural Science Foundation of Shandong Province (No. ZR2017JL020), Taishan Scholarship of Climbing Plan (No. tspd20161006), and the Key Research and Development Program of Shandong Province (No. 2018GGX102028).

\section{Notes and references}

1 Y. Cheng, G. Yang, H. Jiang, S. G. Zhao, Q. Liu and Y. Xie, ACS Appl. Mater. Interfaces, 2018, 10, 38880-38891.

2 Y. Ma, L. Yin, G. Cao, Q. Huang, M. He, W. Wei, H. Zhao, D. Zhang, M. Wang and T. Yang, Small, 2018, 1703613.

3 Y. Wang, W. Wei, X. Liu and Y. Gu, Sol. Energy Mater. Sol. Cells, 2012, 98, 129-145. 
4 X. Li, X. Lv, N. Li, J. Wu, Y. Z. Zheng and X. Tao, Appl. Catal., B, 2019, 243, 76-85.

5 X. Zhang, Y. Guo, J. Tian, B. Sun, Z. Liang, X. Xu and H. Cui, Appl. Catal., B, 2018, 232, 355-364.

6 M. Zhu, S. Kim, L. Mao, M. Fujitsuka, J. Zhang, X. Wang and T. Majima, J. Am. Chem. Soc., 2017, 139, 13234-13242.

7 H. Zhang, G. Liu, L. Shi, H. Liu, T. Wang and J. Ye, Nano Energy, 2016, 22, 149-168.

8 H. Li, X. Zhao, H. Liu, S. Chen, X. Yang, C. Lv, H. Zhang, X. She and D. Yang, Small, 2018, 1802824.

9 L. Hang, T. Zhang, Y. Sun, D. Men, X. Lyu, Q. Zhang, W. Cai and Y. Li, J. Mater. Chem. A, 2018, 6, 19555-19562.

10 P. Li, X. Duan, Y. Kuang, Y. Li, G. Zhang, W. Liu and X. Sun, Adv. Energy Mater., 2018, 8, 1703341.

11 W. Zhang, Y. Zou, H. Liu, S. Chen, X. Wang, H. Zhang, X. She and D. Yang, Nano Energy, 2019, 56, 813-822.

12 Y. Li, Z. Yin, G. Ji, Z. Liang, Y. Xue, Y. Guo, J. Tian, X. Wang and H. Cui, Appl. Catal., B, 2019, 246, 12-20.

13 Y.-N. Liu, C.-C. Shen, N. Jiang, Z.-W. Zhao, X. Zhou, S.-J. Zhao and A.-W. Xu, ACS Catal., 2017, 7, 8228-8234.

14 Y. Tan, Z. Shu, J. Zhou, T. Li, W. Wang and Z. Zhao, Appl. Catal., B, 2018, 230, 260-268.

15 D. Zeng, T. Zhou, W.-J. Ong, M. Wu, X. Duan, W. Xu, Y. Chen, Y.-A. Zhu and D.-L. Peng, ACS Appl. Mater. Interfaces, 2019, 11, 5651-5660.

16 Y. Cui, Z. Ding, X. Fu and X. Wang, Angew. Chem., Int. Ed., 2012, 124, 11984-11988.

17 Y. Li, Y. Xue, J. Tian, X. Song, X. Zhang, X. Wang and H. Cui, Sol. Energy Mater. Sol. Cells, 2017, 168, 100-111.

18 D. Zeng, W. Xu, W.-J. Ong, J. Xu, H. Ren, Y. Chen, H. Zheng and D.-L. Peng, Appl. Catal., B, 2018, 221, 47-55.

19 Y. Chang, Z. Li, X. Shen, B. Zhu, D. K. Macharia, Z. Chen and L. Zhang, J. Hazard. Mater., 2018, 344, 1188-1197.

20 H.-J. Li, D.-J. Qian and M. Chen, ACS Appl. Mater. Interfaces, 2015, 7, 25162-25170.

21 K. Chang, X. Hai, H. Pang, H. Zhang, L. Shi, G. Liu, H. Liu, G. Zhao, M. Li and J. Ye, Adv. Mater., 2016, 28, 10033-10041.

22 D. Lu, H. Wang, X. Zhao, K. K. Kondamareddy, J. Ding, C. Li and P. Fang, ACS Sustainable Chem. Eng., 2017, 5, 1436-1445.

23 N. Qina, J. Xiong, R. Lianga, Y. Liu, S. Zhang, Y. Li, Z. Li and L. Wu, Appl. Catal., B, 2017, 202, 374-380.

24 X.-L. Yin, L.-L. Li, W.-J. Jiang, Y. Zhang, X. Zhang, L.-J. Wan and J.-S. Hu, ACS Appl. Mater. Interfaces, 2016, 8, 15258-15266.

25 Y. Jiang, X. Li, S. Yu, L. Jia, X. Zhao and C. Wang, Adv. Funct. Mater., 2015, 25, 2693-2700.

26 Y. Li, H. Wang, L. Xie, Y. Liang, G. Hong and H. Dai, J. Am. Chem. Soc., 2011, 133, 7296-7299.

27 H. Xu, S. Liu, Z. Ding, S. J. R. Tan, K. M. Yam, Y. Bao, C. T. Nai, M.-F. Ng, J. Lu, C. Zhang and K. P. Loh, Nat. Commun., 2016, 7, 12904.

28 C. Ling, Y. Ouyang, L. Shi, S. Yuan, Q. Chen and J. Wang, ACS Catal., 2017, 7, 5097-5102.

29 J. M. Wu, W. E. Chang, Y. T. Chang and C. K. Chang, Adv. Mater., 2016, 28, 3718-3725.
30 X. Lu, Y. Lin, H. Dong, W. Dai, X. Chen, X. Qu and X. Zhang, Sci. Rep., 2017, 7, 42309.

31 C. Liu, L. Wang, Y. Tang, S. Luo, Y. Liu, S. Zhang, Y. Zeng and Y. Xu, Appl. Catal., B, 2015, 164, 1-9.

32 W. Zhou, Z. Yin, Y. Du, X. Huang, Z. Zeng, Z. Fan, H. Liu, J. Wang and H. Zhang, Small, 2013, 9, 140-147.

33 X. Hao, Z. Jin, H. Yang, G. Lu and Y. Bi, Appl. Catal., B, 2017, 210, 45-56.

34 D. Gopalakrishnan, D. Damien and M. M. Shaijumon, ACS Nano, 2014, 8, 5297-5303.

35 W. Gu, Y. Yan, C. Zhang, C. Ding and Y. Xian, ACS Appl. Mater. Interfaces, 2016, 8, 11272-11279.

36 G. Eda, H. Yamaguchi, D. Voiry, T. Fujita, M. Chen and M. Chhowalla, Nano Lett., 2011, 11, 5111-5116.

37 U. Maitra, U. Gupta, M. De, R. Datta, A. Govindaraj and C. N. R. Rao, Angew. Chem., Int. Ed., 2013, 125, 13295-13299.

38 D. Voiry, M. Salehi, R. Silva, T. Fujita, M. Chen, T. Asefa, V. B. Shenoy, G. Eda and M. Chhowalla, Nano Lett., 2013, 13, 6222-6227.

39 Q. Li, Q. Shang, A. Khalil, Q. Fang, S. Chen, Q. He, T. Xiang, D. Liu, Q. Zhang, Y. Luo and L. Song, ChemCatChem, 2016, 8, 1-7.

40 D. Ruan, S. Kim, M. Fujitsuka and T. Majima, Appl. Catal., B, 2018, 238, 638-646.

41 S. Martha, A. Nashim and K. M. Parida, J. Mater. Chem. A, 2013, 1, 7816-7824.

42 L. Kong, Y. Ji, Z. Dang, J. Yan, P. Li, Y. Li and S. Liu, Adv. Funct. Mater., 2018, 28, 1800668.

43 X. L. Yin, L. L. Li, W. J. Jiang, Z. Yun, Z. Xiang, L. J. Wan and J. S. Hu, ACS Appl. Mater. Interfaces, 2016, 8, 15258.

44 M. Liu, F. Li, Z. Sun, L. Ma, L. Xu and Y. Wang, Chem. Commun., 2014, 50, 11004-11007.

45 W.-J. Ong, L. K. Putri, L.-L. Tan, S.-P. Chai and S.-T. Yong, Appl. Catal., B, 2016, 180, 530-543.

46 A. Thomas, A. Fischer, F. Goettmann, M. Antonietti, J. Müller, R. Schlçgl and J. M. Carlsson, J. Mater. Chem., 2008, 18, 4893.

47 Y. Chang, Z. Liu, X. Shen, B. Zhu, D. K. Macharia, Z. Chen and L. Zhang, J. Hazard. Mater., 2018, 344, 1188-1197.

48 J. Li, Y. Yin, E. Liu, Y. Ma, J. Wan, J. Fan and X. Hu, J. Hazard. Mater., 2017, 321, 183-192.

49 M. A. Lukowski, A. S. Daniel, F. Meng, A. Forticaux, L. Li and S. Jin, J. Am. Chem. Soc., 2013, 135, 10274-10277.

50 Q. Liu, Q. Fang, W. Chu, Y. Wan, X. Li, W. Xu, M. Habib, S. Tao, Y. Zhou, D. Liu, T. Xiang, A. Khalil, X. Wu, M. Chhowalla, P. M. Ajayan and L. Song, Chem. Mater., 2017, 29, 4738-4744.

51 N. Li, J. Zhou, Z. Sheng and W. Xiao, Appl. Surf. Sci., 2018, 430, 218-224.

52 X. Ren, L. Pang, Y. Zhang, X. Ren, H. Fan and S. Liu, J. Mater. Chem. A, 2015, 3, 10693-10697.

53 X. Geng, W. Sun, W. Wu, B. Chen, A. Al-Hilo, M. Benamara, H. Zhu, F. Watanabe, J. Cui and T. P. Chen, Nat. Commun., 2016, 7, 10672.

54 Z. Liang, X. Bai, P. Hao, Y. Guo, Y. Xue, J. Tian and H. Cui, Appl. Catal., B, 2019, 243, 711-720.

55 Y. Li, X. Deng, J. Tian, Z. Liang and H. Cui, Appl. Mater. Today, 2018, 13, 217-227. 
56 B. Han, S. Liu, N. Zhang, Y. J. Xu and Z. R. Tang, Appl. Catal., B, 2017, 202, 298-304.

57 A. Meng, J. Zhang, D. Xu, B. Cheng and J. Yu, Appl. Catal., B, 2016, 198, 286-294.

58 X. Hu, S. Lu, J. Tian, N. Wei, X. Song, X. Wang and H. Cui, Appl. Catal., B, 2019, 24, 329-337.
59 L. Shen, M. Luo, Y. Liu, R. Liang, F. Jing and L. Wu, Appl. Catal., B, 2015, 166-167, 445-453.

60 Y. Hou, A. B. Laursen, J. Zhang, G. Zhang, Y. Zhu, X. Wang, S. Dahl and I. Chorkendorff, Angew. Chem., Int. Ed., 2013, 125, 3709-3713.

61 T. N. Trung, D. B. Seo, N. D. Quang, D. Kim and E. T. Kim, Electrochim. Acta, 2018, 260, 150-156. 